\title{
Multipolar traction with homemade "spider" device to improve submucosal dissection of gastric superficial lesions is safe and effective
}

In recent years, endoscopic submucosal dissection (ESD) has been a revolution for en bloc resection of large superficial tumors of the digestive tract including the stomach. The European Society of Gastrointestinal Endoscopy recommends ESD as the treatment of choice for most gastric superficial neoplastic lesions [1]. However, it remains a time-consuming technique with a long learning curve. Several suggestions have been made in order to improve the technique [2-5], but the lateral and distal edges of the incision remain tricky sections.

Here, we report the case of an 83-yearold man followed for 2 years for a precancerous lesion located in the antrum of the stomach. The latest biopsies showed superficial adenocarcinoma. Computer tomography did not show any lymph node invasion or metastasis. Endoscopic examination and endoscopic ultrasonography showed that the lesion was confined to the mucosal layer, and so in accordance with the recommendations an ESD was proposed.

As shown in Fig. 1, Fig. 2, and - Video 1, we employed a multipolar traction system using a homemade "spider" device with a central rubber band attached with four circular wires. The system was installed just after performing the circumferential incision, fixing metallic clips to the distal and lateral poles of the lesion. Finally, the rubber band was attached to the opposite wall to ease visualization of the dissection line, especially in the final steps. Dissection was subsequently easily and safely performed thanks to this multipolar traction.

This new multipolar traction system is effective because it allows constant stretching of the lesion during the procedure, including on the lateral and distal edges, which are often technically difficult sections. This new technique needs

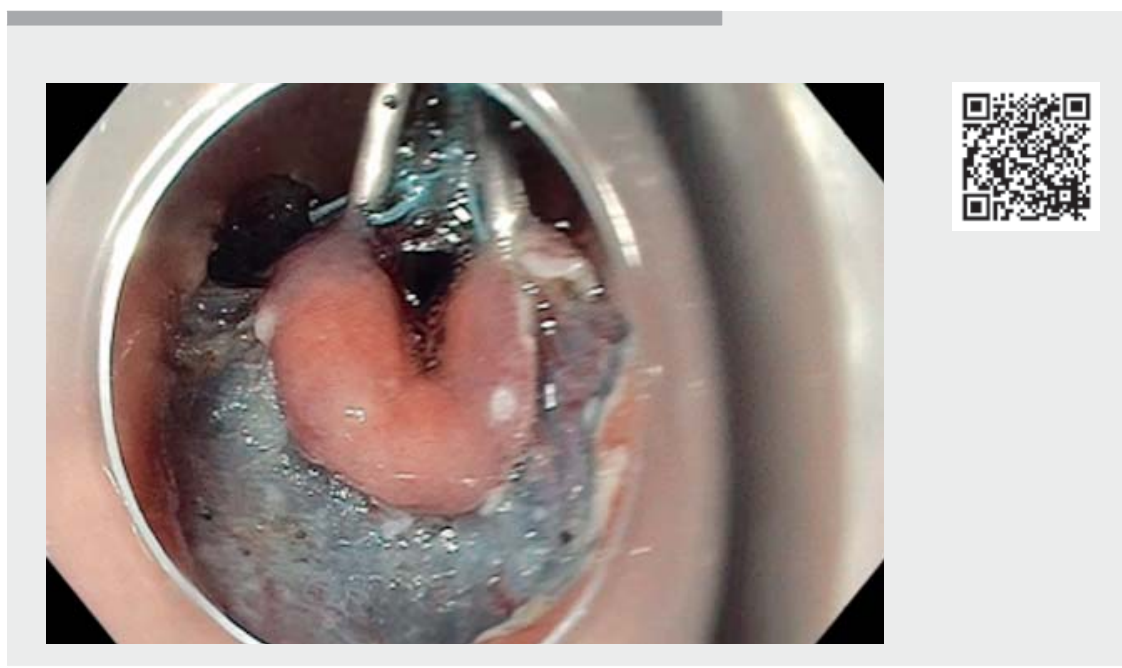

Video 1 Submucosal dissection of a superficial gastric adenocarcinoma using a multipolar traction system.

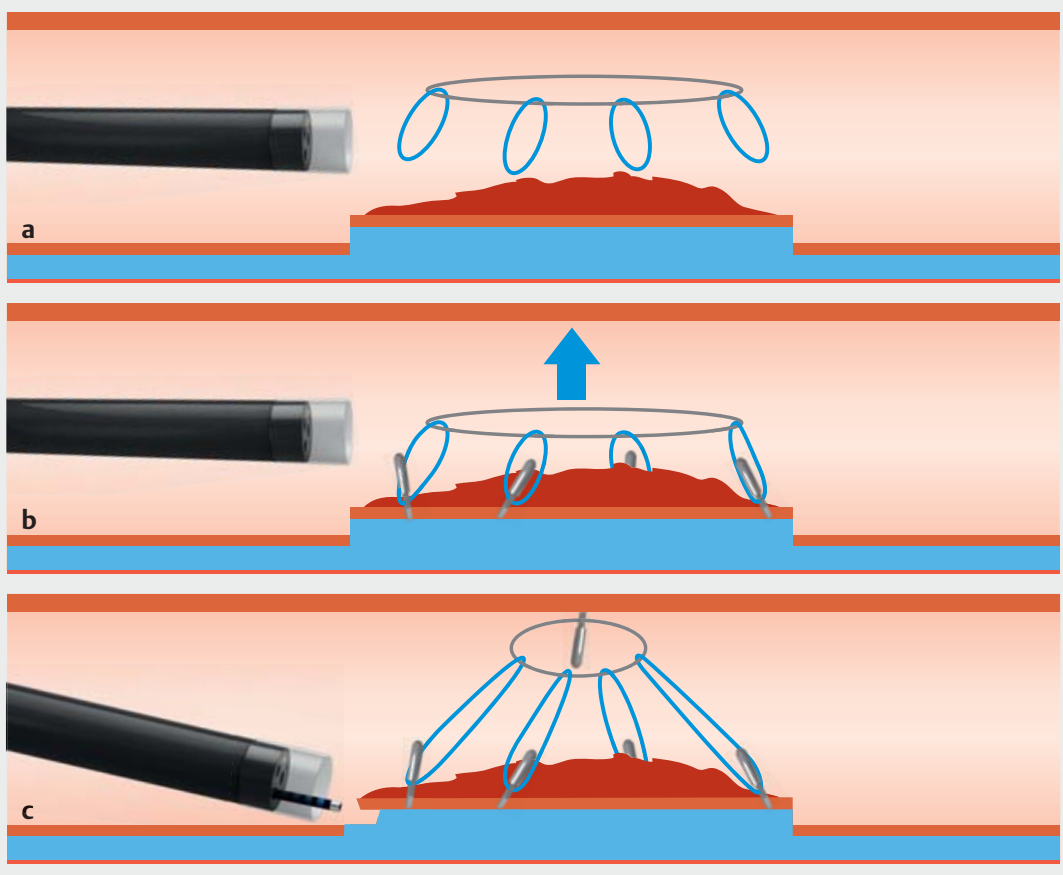

Fig. 1 a-c Schematic representation of the multipolar traction system. a Multipolar traction system brought to the operation site. $\mathbf{b}$ Fixation to each pole of the lesion with endoclips. c Countertraction to the opposite mucosal wall. 

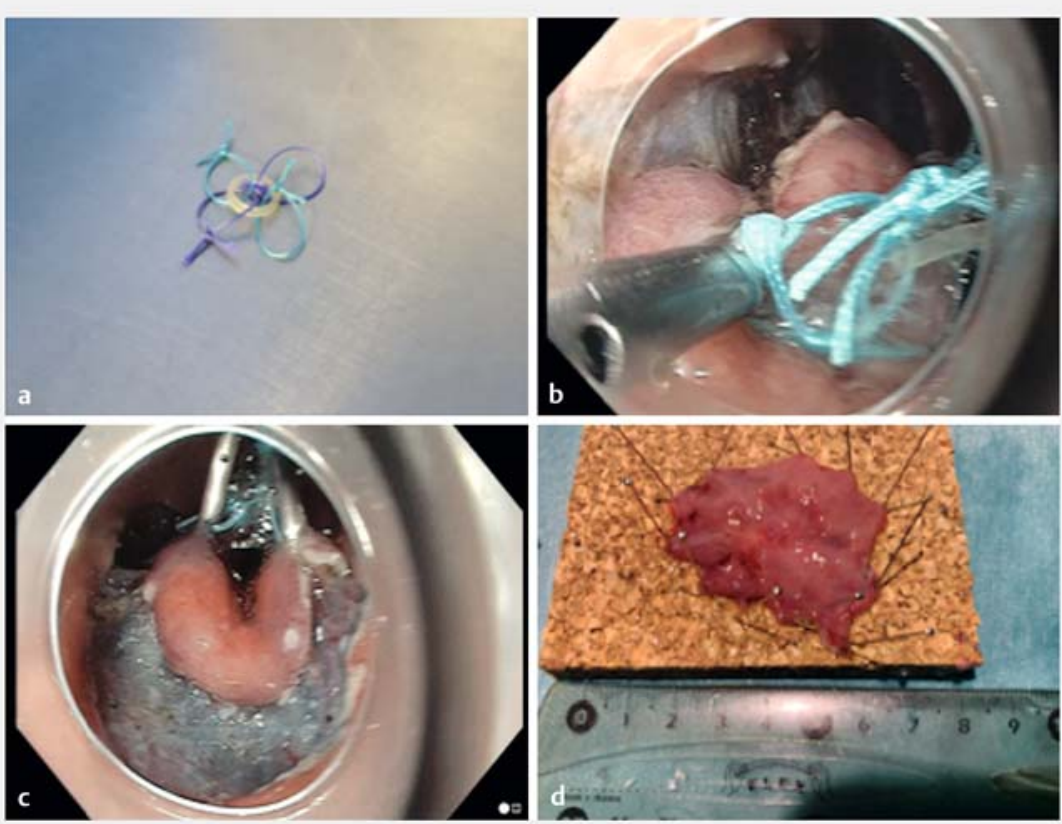

- Fig. 2 a-d Steps in the fixation of the multipolar traction system. a Pre-prepared multipolar traction system. b Pole fixation with endoclip. c Result of the countertraction. d Piece of superficial adenocarcinoma.

to be evaluated but could be added to the panel of dissection strategies to improve the efficacy and safety of the procedure.

Endoscopy_UCTN_Code_TTT_1AO_2AC

\section{Competing interests}

The authors declare that they have no conflict of interest.

The authors

Martin Bordet ${ }^{1,2}$, Thomas Lambin ${ }^{1}$, Timothée Wallenhorst ${ }^{2}$, Jérôme Rivory ${ }^{1}$, Jérémie Jacques $^{3}$, Lucile Héroin ${ }^{1}$, Mathieu Pioche ${ }^{1}$

1 Department of Endoscopy and

Hepatogastroenterology, Pavillon L, Edouard Herriot Hospital, Lyon, France

2 Department of Endoscopy and Gastroenterology, Centre Hospitalier Universitaire Pontchaillou, Rennes, France
3 Department of Endoscopy and Gastroenterology, Centre Hospitalier Universitaire Dupuytren, Limoges, France

\section{Corresponding author}

\section{Mathieu Pioche, MD, PhD}

Endoscopy Unit, Digestive Disease Department, Pavillon L, Edouard Herriot Hospital, 69437 Lyon Cédex, France mathieu.pioche@chu-lyon.fr

\section{References}

[1] Pimentel-Nunes P, Dinis-Ribeiro M, Ponchon $T$ et al. Endoscopic submucosal dissection: European Society of Gastrointestinal Endoscopy (ESGE) Guideline. Endoscopy 2015; 47: 829-854. doi:10.1055/s-0034-1392882

[2] Bordillon P, Pioche M, Wallenhorst T et al. Double-clip traction for colonic endoscopic submucosal dissection: a multicenter study of 599 consecutive cases (with video). Gas- trointest Endosc 2021. doi:10.1016/j. gie.2021.01.036

[3] Abe S, Wu SYS, Ego M et al. Efficacy of current traction techniques for endoscopic submucosal dissection. Gut Liver 2020; 14 : 673-684. doi:10.5009/gnl19266

[4] Lupu A, Jacques J, Rivory J et al. Endoscopic submucosal dissection with triangulated traction with clip and rubber band: the "wallet" strategy. Endoscopy 2018; 50: E256-E258. doi:10.1055/a-0624-1721

[5] Lafeuille P, Rivory J, Jacques J et al. Diagnostic endoscopic submucosal dissection for invasive cancer with the four cardinal points traction strategy. Endoscopy 2021. doi:10.1055/a-1516-3680

\section{Bibliography}

Endoscopy 2022; 54: E554-E555

DOI 10.1055/a-1682-6685

ISSN 0013-726X

published online 19.11.2021

(C) 2021. Thieme. All rights reserved.

Georg Thieme Verlag KG, Rüdigerstraße 14,

70469 Stuttgart, Germany

\section{ENDOSCOPY E-VIDEOS}

https://eref.thieme.de/e-videos

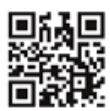

Endoscopy E-Videos is an open access online section, reporting on interesting cases and new techniques in gastroenterological endoscopy. All papers include a high quality video and all contributions are freely accessible online. Processing charges apply (currently EUR 375), discounts and wavers acc. to HINARI are available.

This section has its own submission website at https://mc.manuscriptcentral.com/e-videos 